\title{
PENINGKATAN HASIL BELAJAR IPA SISWA KELAS VIII SMP PARULIAN 1 MEDAN MENGGUNAKAN MODEL PEMBELAJARAN INKUIRI BERBANTUAN ANIMASI
}

\author{
Mariana Br Surbakti ${ }^{1}$, Arjo Saputra Sitorus ${ }^{2}$, Parlindungan Sitorus ${ }^{3}$ \\ Fakultas Ilmu Keguruan, Universitas HKBP Nommensen Medan \\ E-mail: marianasurbakti@uhn.ac.id ${ }^{1}, \underline{\text { arjositorus@gmail.com }}{ }^{2}$, \\ parlindungansitorus@uhn.ac.id ${ }^{3}$
}

\begin{abstract}
This research is motivated by the low science scores of students at the school, so researchers want to conduct research to find out if there is an increase in student learning outcomes in science when using the animation-assisted inquiry learning model. This type of research is quasi-experimental, the research design used is Two Group Pretest-Posttest Design, eighth and the research population is all grade students of SMP Swasta Parulian 1 Medan. The instrument used in the learning outcomes test was 20 multiple choice questions which were validated by 2 science teachers in junior high school. The research result shows the score average pretest of 37.80 in 40.00 in the experimental class and control class and score posttest of 82.00 in 71.00 in the experimental class and control class. Each sample group has normal data and has been tested using the Lilliefors test using SPSS, with the calculation of theresults pretestobtained that Lsignificance $>0.05$, namely $(0.114>0.05)$ for the experimental class and $(0.148>0.05)$ for the experimental class. control, and theresults posttestobtained that Lsignificance $>0.05$, namely $(0.066>0.05)$ for the experimental class and $(0.071>0.05)$ for the control class. Furthermore, the data for both samples have homogeneous variances and have been tested using the SPSS F test, with the calculation of theresults pretestobtained that Fsignificance $>0.05(0.728>0.05)$, and theresults posttestobtained that Fsignificance $0.05(0.050 \geq$ $0.050)$. The research hypothesis test was carried out using the t-test (one-sided test). From the calculation results, it is obtained that thetsignificance $<0.05$ is $(0.000<0.05)$. then the result of hypothesis $\mathrm{Ha}$ isaccepted. Based on the results of the overall data analysis, thetsignificance of $<\mathrm{t}$ is $(0.000<0.05)$ and simple regression analysis $\mathrm{Y}=\mathrm{a}+\mathrm{bx}$ is $\mathrm{Y}=38.347+0.573 \mathrm{x}$. Inquiry learning model assisted by animation media can improve student learning outcomes with a large effect of increasing learning outcomes $15.5 \%$ which has a correlation coefficient of $r=$ 0.491 (medium positive correlation). In conclusion, science learning outcomes using an inquiry learning model assisted by animation media can increase student learning outcomes by $15.5 \%$.
\end{abstract}

Keywords: Inquiry Learning Model, Animation, Learning Outcomes

\section{PENDAHULUAN}

Guru-guru masih cendrung mengajar menggunakan metode ceramah dalam mengajar. Metode ceramah merupakan penyajian informasi secara lisan baik formal maupun nonformal. Metode ceramah cendrung berpusat kepada guru, sehingga siswa tidak aktif dikelas. Dalam metode ceramah, siswa hanya mendengarkan dan mencatat yang pokok-pokok 
yang dikemukakan oleh guru(Surbakti M, dkk. 2021). Siswa cendrung memberi pengertian yang lain darihal yang dimaksudkan oleh guru. Didalam melakukan pembelajaran, metode ceramah kurang efektif dilakukan karena tidak memberi kesempatan pada siswa untuk aktif dalam pembelajaran, sehingga kemampuan belajar siswa pada pembelajaran fisika masih rendah.

Berdasarkan hasil observasi yang dilakukan penulis di SMP Swasta Parulian 1 Medan dapat dilihat kemampuan belajar fisika siswa kelas VIII masih tergolong rendah yang terlihat pada nilai ujian harian siswa. Siswa juga terlihat tidak aktif selama mengikuti proses pembelajaran.

Cara yang dapat digunakan agar proses pembelajaran dapat berjalan sesuai dengan tujuan pendidikan adalah melibatkan siswa untuk aktif dan kreatif agar dapat merumuskan dan menemukan sendiri pembelajaran yang dilakukan. Hal ini bertujuan untuk meningkatkan kemampuan dan hasil belajar siswa dalam mengikuti pembelajaran yang berlangsung. Pembelajaran yang melibatkan siswa untuk aktif adalah dengan menerapkan pembelajaran inkuiri, dimana siswa diberi kesempatan untuk melakukan penemuan secara mandiri. Siswa berperan untuk menemukan sendiri inti dari materi pelajaran. Banyak penelitian yang mengatakan bahwa model pembelajaran inkuiri cocok diterapkan dalam pembelajaran IPA(Iswatun, dkk. 2017)

Hasil penelitian Niniati, dkk (2019)menyatakan bahwa menerapkan model pembelajaran inkuiri dapat meningkatkan kemampuan dan hasil belajar siswa. Penelitian lainnya dilakukan oleh Dian, dkk (2017) menyatakan bahwa pembelajaran inkuiri dapat meningkatkan hasil belajar siswa. Dari hasil penelitian tersebut membuat penulis terdorong untuk melakukan penelitian dengan model pembelajaran inkuiri.

Berdasarkan uraian diatas, bahwa penerapan model pembelajaran inkuiri diharapkan dapat meningkatkan kemampuan belajar dan hasil belajar siswa, sehingga penulis terdorong untuk melakukan penelitian dengan judul :

"Peningkatan hasil belajar IPA siswa kelas VIII SMP Parulian 1 Medan menggunakan model pembelajaran inkuiri berbantuan animasi” 


\section{METODOLOGI PENELITIAN}

\section{Tempat dan Waktu Penelitian}

Penelitian ini dilakukan di kelas VIII SMP Swasta Parulian 1 Medan.Dilaksanakan satu bulan yaitu pada bulan Juni 2019, di semester genap T. P. 2020/2021.

\section{Populasi dan Sampel Penelitian}

Populasi adalah seluruh siswa kelas VIII semester genap SMP Swasta Parulian 1 Medan. Sampel ada dua kelas yaitu kelas eksperimen dan kelas kontrol. Untuk menentukan masing-masing kelas maka peneliti menggunakan metode cluster random sampling.

\section{Variabel Penelitian}

\section{Variabel Bebas $(\mathrm{X})$}

Variabel bebas dalam penelitian ini adalah aktivitas peserta didik dengan menggunakan model pembelajaran Inkuiri dengan media animasi.

\section{Variabel Terikat(Y)}

Variabel terikat adalah hasil belajar siswa pada materi pokok getaran dan gelombang.

\section{Rancangan Penelitian}

Jenis penelitian quasi eksperimen, desain penelitian yaitu Two Group Pretest-Posttest Design(Indra Jaya, 2019).Penelitian melibatkan dua kelas yang diberi perlakuan berbeda dan rancangan penelitian ini dapat dibatasi sebagai berikut:

\begin{tabular}{|l|c|c|c|}
\hline \multicolumn{1}{|c|}{ Desain } & Pretes & Perlakuan & Postes \\
\hline Kelas Eksperimen & $\mathrm{T} 1$ & $\mathrm{X} 1$ & $\mathrm{~T} 2$ \\
\hline Kelas Kontrol & $\mathrm{T} 1$ & $\mathrm{X} 2$ & $\mathrm{~T} 2$ \\
\hline
\end{tabular}




\section{Prosedur Penelitian}

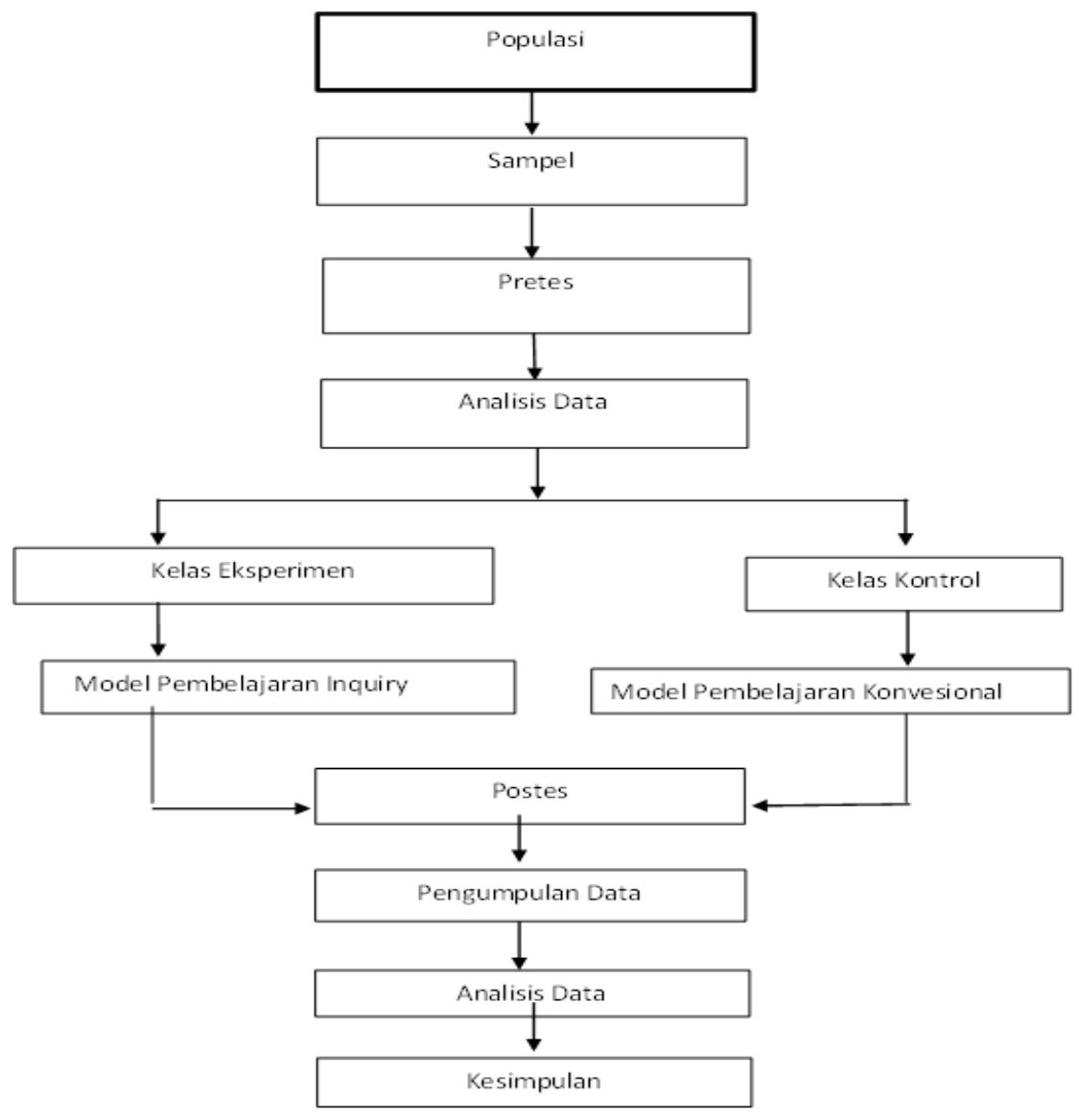

Gambar 1. Bagan alur Proses Penelitian

Metode pengumpulan data yang digunakan adalah metode dokumentasi, metode tes, dan metode observasi (Sugiyono, 2019). Analisa data yang dilakukan analisa statistik (Sudjana, 2016) yaitu analisis uji coba tes berupa uji validitas, reliabilitas, taraf kesukaran, analisis data tahap awal berupa uji normalitas, uji homogenitas. Uji tahap akhir yaitu uji t hipotesis, uji regresi, dan uji korelasi.

\section{HASIL DAN PEMBAHASAN}

\section{Hasil}

Hasil penelitian yang diperoleh dari penggunaan model pembelajaran inkuiriantara lain sebagaiberikut: 
1. Hasil Pembelajaran.

Sebelum dilakukan proses pembelajaran,terlebih dahulu diadakan tes kemampuan awal mahasiswa (pretest) baik padakelas eksperimen maupun pada kelas kontrol. Tujuan diadakanpretestini adalah untuk mengetahui bahwa rata-rata kemampuan siswa antara kelas eksperimen dengan kelas kontrolsama.

a. $\quad$ Pretest

Tabel 1. Data Pretest Mahasiswa Sumber: Hasil Olahan Data Pretest Siswa

\begin{tabular}{|l|l|l|l|}
\hline \multirow{2}{*}{ Sumber Data } & \multicolumn{2}{|l|}{ Nilai } & \multirow{2}{*}{ Mean } \\
\cline { 2 - 3 } & Min & Max & \\
\hline $\begin{array}{l}\text { Kelas } \\
\text { Eksperimen }\end{array}$ & 25 & 55 & 37,80 \\
\hline Kelas Kontrol & 25 & 65 & 40,00 \\
\hline
\end{tabular}

Berdasarkan Tabel 1,dapat dijelaskan bahwakelas eksperimen dan kelas kontrol memiliki nilai rata-rata kelas mean yang tidak terlalu beda jauh. Nilai rata-rata kelas pada kelas eksperimen adalah 37,80 dan nilai ratarata kelas pada kelas kontrol adalah 40,00. Berdasarkan nilai rata-rata data pretest mahasiswa di atas, dapat disimpulkan bahwa baik pada kelas eksperimen maupun kelas kontrolmemiliki kemampuan yang relative sama.

b. Posttest

Tabel 2. Data Posttest Mahasiswa Sumber : Hasil Olahan Data Pretest Siswa

\begin{tabular}{|l|l|l|l|}
\hline \multirow{2}{*}{ Sumber Data } & \multicolumn{2}{|c|}{ Nilai } & \multirow{2}{*}{ Mean } \\
\cline { 2 - 3 } & Min & Max & \\
\hline Kelas & 70 & 95 & 82,00 \\
Eksperimen & & & \\
\hline Kelas Kontrol & 60 & 80 & 71,00 \\
\hline
\end{tabular}

Berdasarkan Tabel 2, dapat dijelaskan bahwa setelah dilakukan pembelajaran dengan model yang berbeda, nilai rata-rata kelas eksperimen adalah 82,00, sedangkan nilai rata-rata kelas kontrol 71,00. Dari hasil perhitungan data diatas, diperoleh hasil belajar kelas 
eksperimen yang dilakukan dengan pembelajaran model inkuiri berbantuan animasi lebih besar dari kelas kontrol yang dilakukan dengan model konvensional.

Sebelum melakukan analisis lebih lanjut, maka terlebih dahulu dilakukan pengujian prasyarat analisis. Pengujian dilakukan dengan uji normalitas dan uji homogenitas.

1) Uji Normalitas

Uji normalitas bertujuan untuk mengetahui apakah kedua sampel berasal dari populasi yang berdistribusi normal atau tidak.

Tabel 3. Uji Normalitas Data

\begin{tabular}{|c|l|c|c|c|}
\hline Data & \multicolumn{1}{|c|}{ Kelas } & L $_{\text {Sig }}$ & $\alpha$ & $\begin{array}{c}\text { Kesimp } \\
\text { ulan }\end{array}$ \\
\hline \multirow{2}{*}{ Pretest } & Eksperimen & 0,114 & & \\
& & & \multirow{2}{*}{0,05} & \multirow{2}{*}{ Normal } \\
\cline { 2 - 3 } & Kontrol & 0,148 & & \\
\hline Posttest & Eksperimen & 0,066 & & \\
\cline { 2 - 3 } & Kontrol & 0,071 & & \\
\hline
\end{tabular}

Dari tabel diatas diketahui bahwa data pretestdan posttest kelas eksperimen dan kelas kontrol yaitu $\mathrm{L}_{\text {signifikansi }}>0,05$ maka data dapat disimpulkan bahwa data berasal dari populasi yang berdistribusi normal.

2) Uji Homogenitas

Uji homogenitas bertujuan untuk mengetahui apakah kedua sampel berasal dari populasi yang homogen atau tidak.

Tabel 4. Uji Homogenitas Data

\begin{tabular}{|c|c|c|c|}
\hline Data & $\mathrm{F}_{\text {Sig }}$ & $\alpha$ & Kesimpulan \\
\hline Pretest & 0,728 & \multirow{2}{*}{0,05} & \\
& & & Homogen \\
\cline { 1 - 2 } Posttest & 0,050 & & \\
\hline
\end{tabular}


Dari tabel di atas diketahui bahwa data postes kelas eksperimen dan kelas kontrol adalah nilai signifikansi $\geq 0,05$. Maka dapat dikatakan bahwa data penelitian adalah Homogen, sehingga dapat digunakan untuk mewakili seluruh populasi.

2. Pengujian Hipotesis

a) Uji Hipotesis Pretes yaitu uji hipotesis dengan menggunakan uji t. Untuk mengetahui adanya kesamaan (tidak berbeda secara signifikan) pada kemampuan awal siswa pada kelas eksprimen dan kelas kontrol, maka digunakan uji t dua pihak.

Tabel 5. Uji Hipotesis Pretest

\begin{tabular}{|c|c|c|c|c|}
\hline No & Data & $\mathrm{T}_{\text {sig }}$ & $\alpha$ & Kesimpulan \\
\hline 1. & $\begin{array}{l}\text { Pretest } \\
\text { Kontrol }\end{array}$ & \multirow[b]{2}{*}{0,287} & \multirow[b]{2}{*}{0,05} & \multirow{2}{*}{$\begin{array}{l}\text { Mempunyai } \\
\text { kemampuan } \\
\text { awal yang } \\
\text { sama }\end{array}$} \\
\hline 2. & $\begin{array}{l}\text { Pretest } \\
\text { eksperi } \\
\text { men }\end{array}$ & & & \\
\hline
\end{tabular}

Dari tabel di atas diketahui bahwa data pretes kelas eksperimen dan kelas kontrol adalah $t_{\text {signifikansi }}>$ tyaitu $(0,278>0,05)$ Sehingga Ho diterima dengan kesimpulan bahwa kemampuan awal siswa kelas eksprimen dan kelas kontrol sama.

a. Uji Hipotesis Posttest

Uji hipotesis postes menggunakan uji t satu pihak dengan tujuan untuk mengetahui ada tidaknya pengaruh model pembelajaran inkuiri berbantuan media animasi dengan pendekatan saintifik sedangkan pada kelas kontrol diberikan perlakuan dengan menerapkan model Pembelajaran konvensional.

Tabel 6. Uji Hipotesis Pretest

\begin{tabular}{|l|l|l|l|l|}
\hline No & Data & $\mathrm{t}_{\text {sig }}$ & $\mathrm{A}$ & Kesimpulan \\
\hline
\end{tabular}




\begin{tabular}{|c|l|l|c|l|}
\hline 1. & Postes & \multirow{2}{*}{0,000} & 0,05 & $\begin{array}{l}\text { Ada pengaruh media } \\
\text { Animasir dalam } \\
\text { Kontrol }\end{array}$ \\
\cline { 1 - 2 } 2. & $\begin{array}{l}\text { Postes } \\
\text { Eksperimen }\end{array}$ & & & pembelajaran inkuiri \\
\hline
\end{tabular}

Dari tabel di atas diketahui bahwa data postes kelas eksperimen dan kelas kontrol adalah $\mathrm{t}_{\text {signifikansi }}<$ tyaitu $(0,000<0,05)$ sehingga Ha diterima dengan kesimpulan bahwa terdapat pengaruh model pembelajaran inkuiri berbantuan media animasi dengan pendekatan saintifik yang signifikan terhadap kemampuan belajar siswa pada materi Getaran dan Gelombang dikelas VIII SMP Swasta Parulian 1 Medan.

Hasil Pengujian Hipotesis :

$$
\begin{aligned}
\% & =\frac{\overline{\mathrm{X}} \text { Eksperimen Postest }-\overline{\mathrm{X}} \text { Kontrol Postest }}{\overline{\mathrm{X}} \text { Kontrol Potest }} \times 100 \% \\
\% & =\frac{82,00-71,00}{71,00} \times 100 \% \\
\% & =15,5 \% \\
3 . & \text { Uji Regresi }
\end{aligned}
$$

\begin{tabular}{|c|c|c|c|c|c|c|}
\hline \multicolumn{7}{|c|}{ Coefficients $^{a}$} \\
\hline \multirow{2}{*}{\multicolumn{2}{|c|}{ Model }} & \multicolumn{2}{|c|}{$\begin{array}{c}\text { Unstandardized } \\
\text { Coefficients }\end{array}$} & \multirow{2}{*}{$\begin{array}{c}\text { Standardized } \\
\text { Coefficients }\end{array}$} & \multirow[t]{2}{*}{$t$} & \multirow[t]{2}{*}{ Sig. } \\
\hline & & $B$ & Std. Error & & & \\
\hline \multirow[t]{8}{*}{1} & (Consta & 3 & 16.209 & & 2. & .027 \\
\hline & $\mathrm{nt})$ & 8. & & & 36 & \\
\hline & & 3 & & & 6 & \\
\hline & & 4 & & & & \\
\hline & & 7 & & & & \\
\hline & variabel & .5 & .212 & .491 & 2. & .013 \\
\hline & $x$ & 7 & & & 70 & \\
\hline & & 3 & & & 4 & \\
\hline
\end{tabular}

Regresi sedehana bertujuan untuk mempelajari hubungan atau pengaruh antara variabel bebas dan variabel terikat.

Tabel 7. Uji Regresi Pretest 
a. Dependent Variable: Variabel Y

Persamaan regresi yang digunakan dikemukakan oleh sudjana yaitu $\mathrm{Y}=\mathrm{a}+\mathrm{bX}$. Dari data hasil penelitian diperoleh persamaan regresi sebagai berikut : $\mathrm{Y}=38,347+0,573 \mathrm{X}$. Dari persamaan tersebut kofisien arah regresi linear $(b)=0.573$. Bertanda positif artinya terdapat hubungan antara aktivitas belajar dengan kemampuan belajar siswa.

4. Uji Korelasi

Uji korelasi dimaksudkan untuk melihat hubungan dari dua hasil pengukuran atau dua variabel yang diteliti, untuk mengetahui derajat hubungan antara variabel $\mathrm{X}$ dengan variabel Y.

Tabel 8. Uji Korelasi

\begin{tabular}{|c|c|c|c|}
\hline \multicolumn{4}{|c|}{ Correlations } \\
\hline & & Variabel & variabel \\
\hline & & $Y$ & $X$ \\
\hline \multirow{4}{*}{$\begin{array}{l}\text { Variabel } \\
\text { Y }\end{array}$} & Pearson & 1 & $.491^{*}$ \\
\hline & Correlation & & \\
\hline & Sig. (2-tailed) & & .013 \\
\hline & $\mathrm{N}$ & 25 & 25 \\
\hline \multirow{4}{*}{$\begin{array}{l}\text { variabel } \\
x\end{array}$} & Pearson & $.491^{\star}$ & 1 \\
\hline & Correlation & & \\
\hline & Sig. (2-tailed) & .013 & \\
\hline & $\mathrm{N}$ & 25 & 25 \\
\hline${ }^{*} . \mathrm{C}$ & is significan & 0.05 & -tailed). \\
\hline
\end{tabular}

Berdasarkan hasil data yang diperoleh, diketahui bahwa nilai signifikan untuk hubungan variabel X dan Variabel Y adalah sebesar 0,013. Karena nilai signifikansinya lebih kecil dari $0,05(0,013<0,05)$, sehingga dapat disimpulkan bahwa terdapat korelasi antara variabel X dan Variabel Y.

Dari data diatas diperoleh bahwa nilai koefisien korelasi sebesar 0,491, maka tingkat hubungan korelasinya termasuk kedalam kategori korelasi sedang. 


\section{ANALISIS DAN HASIL}

Penelitian ini dilaksanakan di SMP Swasta Parulian 1 Medan di kelas VIII. Berdasarkan hasil pengamatan menunjukkan bahwa terdapat peningkatan hasil belajar siswa kelas VIII SMP Swasta Parulian 1 Medan pada mata pelajaran IPA dengan materi Getaran dan Gelombang.

Hasil belajar siswa pada kelas eksperimen lebih besar dari pada kelas kontrol dengan nilai rata-rata posttest kelas eksprimen yaitu 82,00 sedangkan nilai rata-rata posttest kelas kontrol yaitu 71,00. Dari hasil pengujian hipotesis yang diajukan dapat diterima hipotesis alternative (Ha) yaitu data uji hipotesi satu pihak diperoleh bahwa $t_{\text {signifikansi }}<$ tyaitu $(0,000<$ 0,05)). Berdasarkan hasil penelitian ini, dapat disimpulkan bahwa Pembelajaran dengan model pembelajaran inkuiri berbantuan media animasi dengan pendekatan saintifik dapat mempengaruhi kemampuan belajar siswa pada materi pokok Getaran dan Gelombang di kelas VIII SMP Swasta Parulian 1 Medan.

Terdapat persentase pengaruh peningkatan kemampuan belajar siswa sebesar 15,5\% pada kelas eksperimen dan kontrol disebabkan oleh adanya perbedaan pemberian perlakuan terhadap kedua kelas. Di kelas eksperimen diberi perlakuan yaitu model pembelajran inkuiri berbantuan media animasi dengan pendekatan saintifik sedangkan kelas kontrol tetap dijaga pada model pengajaran konvensional. Hal ini sekaligus membuktikan bahwa model pembelajaran inkuiri memberikan pengaruh terhadap peningkatan hasil belajar siswa pada mata pelajaran IPA.

Berdasarkan hasil pengamatan yang dilakukan observer diperoleh peningkatan aktivitas belajar. Jadi, keseluruhan rata-rata aktivitas belajar siswa pada kelas ekprimen adalah 76,2 tergolong dalam kategori baik. Adapun persamaan regresi yang digunakan dalam penelitian ini yang bertujuan melihat hubungan keaktifan siswa dengan hasil belajar adalah: Y $=38,347+0,573 \mathrm{X}$. dari persamaan tersebut koefisien arah regresi linear $(\mathrm{b})=0,573$. Bertanda positif artinya terdapat hubungan yang linear antara aktivitas belajar dengan hasil belajar siswa. Besar pengaruh aktivitas belajar siswa dapat meningkatkan kemampuan belajar siswa sebesar 0,573. Dari hasil penelitian dan analisis data, dapat ditarik kesimpulan bahwa tujuan penelitian ini untuk meningkatkan hasil belajar IPA, siswa di SMP Parulian 1 Medan telah tercapai. 


\section{KESIMPULAN DAN SARAN}

\section{Kesimpulan}

Berdasarkan hasil penelitian dan pembahasan, dapat disimpulkan bahwa :

1. Model pembelajaran inkuiri menggunakanmedia Animasi pada mata pelajaran IPA dengan materi Getaran dan Gelombang Di Kelas VIII SMP Swasta Parulian 1 Medan mampu meningkatkan hasil belajar siswa. Hal ini dapat dibuktikan didalam penelitian ini dengan hasil sebagai berikut :

a) Diperoleh rata-rata untuk kelas eksperimen sebesar 37,00 untuk pretest dan 82,00 untuk posttest, sementara untuk kelas kontrol pretest sebesar 40,00 dan posttestt sebesar 71,00 .

b) Dari aktivitas belajar siswa di kelas eksperimen nilai rata-rata sebesar 76,2. Hal ini membuktikan adanya pengaruh penggunaan model pembelajaran inkuiriberbantuan animasi terhadap kemampuan belajar siswa pada materi pokok Getaran dan Gelombang.

2. Berdasarkan hasil analisis data secara keseluruhan $t_{\text {signifikansi }}<$ tyaitu $(0,000<0,05)$ dan analisis regresi sederhana $\mathrm{Y}=\mathrm{a}+\mathrm{bx}$ adalah $\mathrm{Y}=38,347+0,573 \mathrm{X}$. dapat dilihat bahwa dengan model pembelajaran inkuiri berbantuan media animasi dapat meningkatkan hasil belajar siswa dengan besar pengaruh peningkatan hasil belajar 15,5\% yang mempunyai koefisien korelasi $\mathrm{r}=0,491$ (berkorelasi positif sedang).

\section{Saran}

Untuk mendapatkan hasil yang lebih maksimal, peneliti selanjutnya harus mampu menampilkan media animasi yang lebih baik dan mampu merangsang minat belajar IPA dari siswa SMP. Penelitian ini juga dapat dilanjutkan, sehingga hasil pembelajaran yang diperoleh lebih maksimal lagi.

\section{DAFTAR PUSTAKA}

Dian Puspitasari. Eko Swistoro. Eko Risdianto. 2017., "Pengaruh Penggunaan Model Inkuiri Terbimbing dengan pendekatan saintifik terhadap keterampilan proses sains dan hasil belajar pada materi getaran gelombang dan bunyi di SMPN 08 Bengkulu”, Jurnal Pembelajaran Fisika. Vol. 1. No. 1 (http://ejournal.unib.ac.id/index.php/jipf/article/view/3136, diunduh 1 Agustus 2017) 
Jurnal Visi Eksakta (JVIEKS)

Vol.2, No.2, Juli 2021, pp.174-185

https://ejournal.uhn.ac.id/index.php/eksakta/

Iswatun. M.Mosik. Bambang Subali. 2017.,"Penerapan model pembelajaran inkuiri terbimbing untuk meningkatkan KPS dan hasil belajar siswa SMP kelas VIII”, Jurnal Inovasi Pendidikan IPA. Vol. 3 (2), 150-160. (http://journal.uny.ac.id/index.php/jipi, diunduh oktober 2017)

Jaya, Indra. 2019.,Penerapan Statistik untuk Penelitian Pendidikan, Jakarta: Prenadamedia Group

Kementerian Pendidikan dan Kebudayaan Republik Indonesia. 2017.,Ilmu Pengetahuan Alam, Jakarta : Kementerian Pendidikan dan Kebudayaan.

Niniati. Luh Sukariasih. La Sahara. 2019. "Penerapan Model Inkuiri Terbimbing untuk meningkatkan keterampilan proses sains dan hasil belajar siswa SMPN”,Jurnal Penelitian Pendidikan Fisika. Vol.4 No. 2, 60-72.

(http://ojs.uho.ac.id/index.php/JIPFI/article/view/14186, diunduh 2 April 2019)

Sudjana. 2016.,Metoda Statistika,Bandung : PT Tarsito Bandung.

Sugiyono. 2019. Metode Penelitian Pendidikan (Kualitatif, Kuantitatif, Kombinasi, $R \& D$ dan Penelitian Pendidikan. Bandung: Alfabeta.

Surbakti, Mariana. Romauli Manullang, Januari Pane. 2021. "Pengaruh Model Pembelajaran Problem Based Learning Terhadap Hasil Belajar Siswa Pada Materi Pokok Pesawat Sederhana di Kelas VIII SMPN 14 Medan”. Vol.2 N. 1 Januari 2021,pp.72-85.

Suyatna, Agus. 2017.,Uji Statistik Berbantuan SPSS untuk Penelitian Pendidikan, Yogyakarta : Media Akademi. 